\title{
The development of new business arrangements in the Great Lakes St. Lawrence Forest Region of Ontario
}

\author{
by W.J. Brown R.P.F. \\ A presentation to the 1995 Annual Meeting \\ of the Ontario Professional Foresters Association, \\ Toronto, February 24, 1995
}

\begin{abstract}
Introduction
The January/February 1995 Issue of The Forestry Chronicle included an article by Mr. Bob Carman, Provincial Facilitator, Forest Industry/Ontario Government. The article described the development of a framework for significant changes in the way Ontario and the forest industry fund and manage forest management and renewal on crown land in Ontario.

Mr. Carman and his team focussed on developing the framework and negotiating amendments to the existing forest management agreements in the boreal forest region of the province.

In forest types, forest management systems and industry profile in the Great Lakes St. Lawrence (GLSL) Forest Region was considered sufficiently different to assign the task of adapting the new framework to those conditions separately.

In July of 1994 I was seconded from my duties at the Algonquin Forestry Authority "to assess the applicability of the new business relationship in the Great Lakes St. Lawrence Forest and to adapt the relationship so that it can be implemented by 1 April 1994."

Two key items in the terms of reference were:
\end{abstract}

...identify the appropriate renewal costs and stumpage levels, and assess the feasibility of the residual value concept, in concert with the Ministry of Natural Resources (MNR) and the forest industry.

...develop, negotiate and implement two or three new business relationship models by 1 April 1995 .

\section{The Stumpage System}

A key component of the "Carman Framework" is a stumpage system which is sector specific, has a minimum charge, a renewal charge, and a residual value component. The minimum charge and the residual value flow to the provincial treasury. The renewal charge is deposited into either a trust account or special purpose account to fund "eligible silvicultural expenses" on the landbase from which it was generated.

\section{The Minimum Charge}

This component of stumpage was set at one dollar for $1994 / 95$ and is scheduled to increase through time.

\section{The Renewal Charge}

The Carman Team developed the renewal charges that would apply for the boreal forest. The rates for GLSL species such as white and red pine and tolerant hardwoods were developed separately.

This task was accomplished with the help of a technical advisory committee, comprised of eight Ministry of Natural Resources staff and seven forest industry representatives. The recommended rates have now been identified and final approval is expected in April.

For areas harvested after 1 April 1995, these renewal charges become the dedicated funding for forest renewal work on crown land. The work done with these funds is subject to current silvicultural standards, and both internal and external audit procedures.

\section{The Residual Value Charge}

This charge is based on the selling price for various forest products in the market place. For example, the selling price for spruce/pine/fir lumber, $2 \times 4$, \#2 common and better, FOB Chicago, is the reference price for SPF Lumber. As the reference price rises from a base rate, the residual value charge rises with every $\$ 10.00$ increase in reference price.

The formula for SPF lumber, pulp, paper and oriented strand board was developed by the Carman Team. The technical advisory committee for the GLSL and Ministry of Natural Resources staff have now been able to adapt that formula for application to white and red pine and tolerant hardwoods.

Residual values for white and red pine and tolerant hardwood lumber will be determined in a similar fashion to other sectors, by reference to the selling prices for these products, as reported in published market reports.

The residual value approach has the effect of generating more revenue for the province when selling prices for products are higher and the industry is better able to pay. When selling prices fall and the industry is less able to pay, the residual value declines.

Final approval for this aspect of the stumpage system for the GLSL is also expected in April 1995.

With the identification of appropriate renewal charges and the adaptation of the residual value approach to the GLSL conditions, a key part of the task has been accomplished.

The system will not be static. There are provisions to review the renewal charges after the first two years, and revise those charges either up or down, according to the experience and results. It will be possible to have different renewal charges by management unit after the second year.

The minimum charge and the residual value components also have provisions to adjust them through time.

\section{Developing New Business Relationships}

During the time the stumpage system changes were being designed, meetings were held across the central region, with forest industry and Ministry of Natural Resources staff to explain and discuss options for new business arrangements.

The forest industry profile in the GLSL forest region of Ontario is characterized by many small to medium-sized companies operating hardwood and softwood sawmills, veneer mills, board plants, 
specialty mills, and pulp and paper mills. There is only one forest management agreement where the company has the responsibility for forest management planning and silviculture.

For the majority of the others, the historical pattern has been for the Ministry of Natural Resources to provide the forest management planning, data collection, and silvicultural services on crown land. These companies have had relatively little direct involvement in the delivery of these services.

A primary objective of the "new business relationship" is to have these companies assume more responsibility and assume more of the cost of forest management and forest renewal.

\section{The Options}

\section{A. The Status Quo}

This option will see the Ministry of Natural Resources continue to deliver the necessary planning, data and silvicultural services on behalf of the companies operating on crown management units. The funding for the silviculture will come from the renewal charges paid by the licensees harvesting on the unit.

This option can be attractive for both the industry and the MNR in that it allows both parties to continue with their traditional roles, and requires little change. It is also a necessary option in the short run because in most cases, companies require time to develop the ways and means to be able to effectively deliver such programs.

Many companies recognize, however, that it is in their interest to become involved because they are now paying the costs of silviculture, and only by being involved themselves, will they have some direct influence on the costs that are incurred.

These companies also know that in future, MNR intends to concentrate on those roles that are most vital to ensuring that the provincial interest in resource management is defined and achieved. It is also understood that government constraints and new responsibilities will continue to make it more difficult for MNR to be directly involved in field programs.

\section{B. Forest Renewal Agreements}

Some companies see merit in entering into forest renewal agreements with MNR whereby the company would conduct the required silviculture on the licence areas they operate. The company then has direct influence on the cost of silviculture as well as the timing and scheduling of that work. The timing and scheduling aspect can be an important advantage in controlling the costs of both harvesting and silviculture.

These agreements can be for a single season or for a planning period ( $5 \mathrm{yr}$ ). There is also the opportunity for several smaller companies to cooperate in the delivery of their collective silvicultural requirements in order to achieve some advantages of scale and lower unit costs.

While this option involves the company in the delivery of silviculture, the forest management planning and data collection remains with the MNR.

At the time of writing, several companies that have traditionally focussed on harvesting only are in the process of negotiating forest renewal agreements with MNR. 